\title{
ИНСТИТУТ РЕФЕРЕНДУМА В КОНТЕКСТЕ ЧЛЕНСТВА ГОСУДАРСТВ В ЕВРОПЕЙСКОМ СОЮЗЕ
}

В статье рассматриваются основные вопросы проведения референдумов в отдельных странах-членах Европейского Союза в отношении вопросов, связанных с функционированием и развитием ЕС. Автор даёт характеристику современного значения института референдума в связи с продолжающимися процессами региональной интеграции и участием государств в них на основе делегирования суверенных полномочий. Членство в Европейском Союзе, как международной организации sui generis, предусматривает передачу государствами реализации части своих ключевых суверенных полномочий институтам и органам ЕС. Данный институт неразрывно связан с понятием «суверенитет», а именно с концепцией «народного суверенитета», что предполагает участие граждан в осуществлении функций государства, в том числе, в отношении участия в межгосударственных объединениях. Выражением этого, среди прочего, является институт референдума. Многие государства-члены Европейского Союза используют референдумы для решения вопросов, связанных с процессами европейской региональной интеграции. Автор статьи выделяет три категории референдумов, связанных с членством в ЕС. Во-первых, это референдумы,

касающиеся присоединения к европейскому Союзу. Ко второй категории можно отнести референдумы, касающиеся одобрения международных договоров Союза, которые вносят изменения в учредительные договоры EC. В третью категорию входят референдумы о выходе из состава Европейского Союза. К данной категории относятся референдумы о выходе, проведённые в Великобритании в 1975 и 2016 гг. Если на первом был получен отрицательный результат, то второй референдум стал причиной инициирования процесса выхода Великобритании из Европейского Союза - Brexit. В целом, референдумы как приоритетная форма прямого народовластия продолжают свой генезис на качественно новом уровне: расширяется круг стран, практикующих референдумы с целью принятия общественно значимых решений; увеличивается круг вопросов, выносимых на всенародное голосование, а сами референдумы, проводимые в отдельных государствах, приобретает не только общенациональное, но и международное значение, что подтверждает практика Европейского Союза

Ключевые слова: референдум, членство государств в ЕС, Европейский Союз, суверенитет, Великобритания, Брекзит, Ирландия.

\section{Galushko}

\section{THE INSTITUTE OF REFERENDUM IN THE CONTEXT OF MEMBERSHIP IN THE EUROPEAN UNION}

The article discusses the main issues of holding referendums in particular European Union member-states in relation to issues related to the functioning and development of the EU. The author gives a description of the current importance of the institute of the referendum in connection with ongoing processes of regional integration and the participation of states in them on the basis of delegation of sovereign powers.

Membership in the European Union, as an international organization sui generis, provides for the states' transfer of part of their key sovereign powers to EU institutions and bodies. This institution is inextricably connected with the concept of «sovereignty», namely with the concept of «popular sovereignty», which implies the participation of citizens in the execution of functions of the state, including with regard to participation in interstate entities. An expression of this, among other things, is the institution of a referendum. Many member-states of the European Union use referenda to resolve issues related to European regional integration processes. The author of the paper identifies three catego- ries of referenda related to EU membership. Firstly, these are referenda regarding accession to the European Union. The second category includes referenda regarding the approval of international treaties of the Union, which amend the EU constituent treaties. The third category includes referenda on secession from the European Union. Exit referenda held in the UK in 1975 and 2016 fall into this category. If a negative result was obtained at the first, the second referendum became the reason for initiating the process of Great Britain's exit from the European Union - Brexit. In general, referenda as a priority form of direct democracy continue their genesis at a qualitatively new level: the circle of countries practicing referenda is expanding with the goal of making socially significant decisions; the range of issues submitted to a popular vote is increasing, and the referenda held in individual states are acquiring not only national but also international significance, which is confirmed by the practice of the European Union.

Key words: referendum, EU member states, European Union, sovereignty, United Kingdom, Brexit. 
Рефререндумы, как акты прямого народовластия, выступают важными источниками современного права. Их считают не просто высказыванием народа по определенному вопросу а принятием решения народом по данному вопросу [1, с. 416]. Рефререндумы имеют большое значение для большинства государств и наций поскольку именно решения, принятые на референдумах, легитимизировали независимость многих стран мира, придали силу их конституциям, уладили территориальные споры, разрешили вопросы реформ, оптимизировали их административно-территориальное устройство. Кроме того, именно на референдумах были приняты решения, которые определили отношение народов разных стран мира ко многим международным вопросам, в частности, в отношении членства в различных международных организациях, прежде всего, региональных, среди которых особое место занимает Европейский Союз

Развитие региональных международных организаций в настоящее время зачастую неразрывно ассоциируется с понятием «региональная организация». По мнению некоторых учёных, EC представляет собой сложную многоступенчатую систему, в основу функционирования которой положены принципы, нацеленные на гармонизацию интересов всех участников интеграционного процесса [7, с. 45-46]. Процесс интеграции также характерен и для евразийского региона, на просторах которого в 2015 г. был образован Евразийский Экономический Союз (ЕАЭС). Образование ЕАЭС - результат долгой и трудной эволюции региональных интеграционных процессов в Евразии, которые начались с момента развала СССР и создания Содружества Независимых Государств $[8$, с. 32$]$

Нельзя не отметить поразительное сходство алгоритма развития межгосударственной интеграции в Евразии с процессами, которые привели к созданию современного Европейского Союза (EC) $[9$, c. 130]. Общепризнанно, что Европейский Союз является наиболее развитой организационной формой региональной интеграции, указывается, что опыт ЕС является мерилом эффективности интеграции и образцом для подражания, что интеграционные теории должны опираться в основном на обобщение опыта, успехов и неудач интеграции в рамках ЕC [2, с. 99]. Поэтому учёт опыта различных аспектов функционирования данной международной организации, по нашему мнению, представляется целесообразным.

Общегосударственные референдумы, проводимые в странах в связи с членством в Европейском Союзе или по отдельным вопросам сотрудничества с данной международной организацией стали во многом судьбоносными не только для самих государств, но и для развития правовой системы ЕС. Процесс развития Европейского Союза неоднократно акцентировал внимание на необходимости привлечения граждан к оценке углубления евроинтеграции и расширения границ EC как внутри самой организации, так и в госу- дарствах-кандидатах на вступление и в государствах-партнерах [15].

Принимая во внимание особый характер Европейского Союза как организации sui generis [6], членство государств в ЕС предполагает передачу ими реализациючасти своих ключевых суверенных полномочий институтам и органам данной организации. Тем самым, институт членства государств в ЕС неразрывно связано с категорией «государственный суверенитет», который характеризуется как «юридическое выражение самостоятельности государства, верховенства его власти внутри страны, а также независимости и равноправия во взаимоотношениях с другими государствами» [4, с. 370]. При этом, можно выделить непосредственную связь государственного суверенитета с суверенитетом народным, так как суверенитет государства вытекает из суверенитета государственно-организованного народа и означает не совокупность важных властных полномочий, а особую природу данного политического образования. По этому поводу Н. Н. Марченко отмечает, что «в триаде «общество-государство-государственная власть» первичным звеном является «народный суверенитет», что ассоциируется, как правило, с «народовластием», а затем уже - «государственный суверенитет», как производное свойство или явление от «народного суверенитета»». При этом, носителем государственного суверенитета, а вместе с тем и обладателем суверенных прав и обязанностей является не государственная власть или какой бы то ни было государственный орган, а само государство [10, с. 194].

Народному суверенитету в современных условиях как никогда присущи действенность, активность, конструктивизм, динамизм. Такие элементы, как свойство и способность народа быть верховным и полновластным, недостаточны для понимания народного суверенитета. Народ должен быть не только источником, но и субъектом власти. Именно из этих постулатов исходит большинство основных законов современных демократических государств. Так, Конституция Эстонии в отдельной главе 3 «Народ» в ст. 56 закрепляет, что верховную государственную власть народ осуществляет через граждан, обладающих правом голоса:

1) путем выборов в Государственное Собрание;

2) путем референдума (всенародного голосования) [24]

В национальных правовых системах о суверенитете соответствующего государства речь идёт в первых разделах конституций при общей характеристике самого государства. Например, Конституция Республики Ирландии упоминает суверенитет в двух своих статьях: статья 1 говорит, что «Ирландский народ настоящим утверждает неотьемлемое, неотчуждаемое и суверенное право избирать собственную фрорму правления, определять свои отношения с другими народами и развивать свою политическую, экономическую и культурную жизнь в соответствии с его собственными склонностями и традициями", а статья 5 указывает, что 
«Ирландия является суверенным, независимым и демократическим государством» [25]

Кроме того, Конституция Ирландии содержит положения, касающиеся осуществления суверенных прав (функций) при участии в каких-либо межгосударственных объединениях. В статье 29.4 .2 закреплено, что с целью осуществления любых исполнительных фуннцций государства или относящихся к внешним сношениям Правительство может в пределах и на условиях, определенных законом, использовать или применить любой орган, инструмент или процедуру, используемые или одобряемые для этих целей членами любой группы или союзом народов, с которыми государство объединяется или будет объединяться с целью международного сотрудничества по вопросам, представляющим взаимный интерес [25].

Такое включение государством в свое национальное законодательство нормативных положений, касающихся передачи суверенных прав межгосударственным образованиям, органы которых вправе принимать обязательные для этих государств акты и предписания, выступает как форма реализации своего суверенитета [5].

В целом, когда государство передает некоторые свои суверенные права межгосударственным образованиям, то это не влечет за собой уменьшения суверенных правомочий этих государств. Так как переданное право на реализацию суверенных правомочий компенсируется приобретением так называемых общесистемных полномочий, что влечет за собой расширение радиуса совместной деятельности государств [19].

В качестве примера можно привести опыт Ирландии (впрочем, как и других стран-членов Европейского Союза), которая, став членом ЕС, ни в коей мере не утратила своего суверенитета, поскольку передала, как утверждают некоторые учёные, не сами свои суверенные права, а лишь право их реализации [23, p. 78]. Кроме того, Ирландия может вернуть их себе обратно в полном объеме путем выхода из Союза.

Существенное значение в процессе осуществления суверенитета имеет референдум, путем проведения которого могут решаться не только вопросы принятия и утверждения конституции или иных правовых актов, насущных проблем государственной и общественной жизни, но и, как уже отмечались, вопросы взаимодействия с Европейским Союзом. При этом, учет мнения граждан при реализации евроинтеграционной стратегии государства является важным фактором ее успешности

Например, Норвегия дважды не стала членом EC, хотя два раза подавала заявку на вступление и каждый раз организационно была к этому готова и даже подписала соглашения о вступлении с EC, однако членство этого скандинавского государства в EC не было поддержано гражданами государства на общенациональных референдумах о вступлении.

Так, 22 января 1972 г. был подписан Договор между государствами-членами Европейских Сoобществ с Норвегией, Ирландией, Соединённым
Королевством и Данией, который предусматривал процедуру вступления этих стран в Сообщества [27]. В преамбуле Договора подчеркивалось, что вступление данных государств в Сообщества происходит на основе статьи 237 Договора, учреждающего Европейское экономическое сообщество, 1957 г. и статьи 205 Договора, учреждающего Европейское сообщество по атомной энергии, 1957 г., которые «дают европейским государствам возможность стать членами этих Сообществ».

В соответствии со ст. 2 Договора, он должен был быть ратифицирован вступающими государствами. Договор вступал в действие с 1 января 1973 года. Условия вступления Норвегии, Ирландии, Дании и Соединённого Королевства были определены в «Акте об условиях вступления и внесении изменений в Учредительные Договоры» [12]. Как указывалось, в п. 2 ст. Договора о вступлении, данный «Акт» являлся его неотъемлемой частью [3, с. 61-62]

Однако, уже в сентябре 1972 года 54 \% населения Норвегии проголосовали против присоединения к Сообществам из-за волнения последствий вступления для экономики государства [13]

Следует заметить, что кроме норвежского референдума, в том же году свой плебисцит был проведён в Ирландии. Ирландский референдум преследовал двойную цель - одобрение гражданами вступления страны в Европейские Сообщества, а также внесение изменений в Конституцию (о применении права Сообществ на территории страны и приоритете права Сообществ над национальным правом). Вхождение Ирландии в Сообщества было одобрено населением страны. «За» высказались 1041890 избирателей из 1264278 . явившихся на избирательные участки.

Во второй раз Норвегия подала заявку на вступление в ЕС в ноябре 1992 г. [22] В июне 1994 г Соглашение о вступлении [28] было подписано между Норвегией и ЕС, однако уже в ноябре норвежские граждане снова проголосовали против членства этого государства в Евросоюзе на общенациональном референдуме. Основные вопросы, которые способствовали такому результату, вновь касались экономической сореры, в частности, энергетической политики (Норвегия не хотела отказываться от контроля над ее огромными резервами природного газа и нефти), а сфера рыболовства и другие [18].

Еще одним примером того, как общественное мнение может негативно повлиять на результать участия в процессах европейской интеграции, а именно на стремление вступления в ЕС, является Швейцария. Её граждане выступили против присоединения государства к Европейскому экономическому пространству (ЕЭП) на общенациональном референдуме в декабре 1992 г., после чего правительство Швейцарии приняло решение не продолжать евроинтеграционную политику государства и не ставить целью членство Швейцарии в ЕС [14]. ЕЭП было предложением Европейской комиссии как проект создания большого интегрированного рынка, который включал бы в себя двенадцать государств-членов ЕС и семь 
членов Европейской ассоциации свободной торговли (ЕАСТ): Австрию, Финляндию, Исландию Лихтенштейн, Норвегию, Швецию и Швейцарию [11]. Фактически ЕЭП стал первым неофициальным шагом к интеграции половины государств ЕАСТ в Союз, а именно Австрии, Финляндии и Швеции, которые стали членами Европейского Союза в 1995

В целом, в Европейском Союзе не каждое государство использует национальные референдумы для решения евроинтеграционных вопросов Более того, такая форма привлечения граждан к процессу принятия решений в ЕС использовалась в отношении определенных аспектов, но референдумы со временем стали играть все более важную роль в процессе функционирования Союза. В настоящее время можно выделить три категории вопросов, которые становились предметами общенациональных референдумов в связи с членством государств в Европейском Союзе

В первую категорию можно причислить референдумы, касающиеся присоединения к ЕС. О некоторых из таких референдумов, проводившихся в Норвегии и Ирландии, говорилось выше.

Во вторую категорию можно отнести референдумы, касающиеся одобрения международных договоров Союза, которые вносят изменения в учредительные документы ЕС. Так, в Ирландии в связи с членством страны в ЕC, кроме референдума о вступлении, было проведено восемь референдумов о внесении соответствующих изменений в Конституцию, по итогам которых были внесены шесть поправок (в 1987, 1992, 1998 2002, 2009 и 2012 гг.). При чём результаты ирландских референдумов как минимум в двух случаях (по вопросам ратификации Ниццкого и Лиссабонского договоров) имели чрезвычайно важное значение для развития Европейского Союза и всего процесса европейской интеграции. И Ниццкий и Лиссабонский договоры были ратифицированы Ирландией в результате проведения повторных референдумов, так как на первоначальных голосованиях были получены отрицательные результаты. Это не только не давало возможности ратифиццировать договоры государством, но и откладывало вступление их в силу в принципе [20].

Первый ирландский референдум по вопросу ратификации Лиссабонского договора, проведенный 12 июня 2008 г., не только поставил большой знак вопроса перед сторонниками усиления интеграционных процессов на Европейском континенте, но и еще раз заставил обратить внимание на существующие проблемные моменты в сфере государственного строительства стран Единой Европы. Речь идет, прежде всего, о соотношении институтов непосредственной и представительной демократии при решении вопросов, связанных с функционированием Европейского Союза Ратификационный процесс еще раз подтвердил, что ставить знак равенства между этими двумя формами в современных условиях практически невозможно. И прежде всего из-за того, что на фоне практически беспроблемного решения вопроса ратификации Лиссабонского договора парламентами восемнадцати других стран-членов EC, предшествовавшего ирландскому peфpeрендуму, граждане Ирландии на специальном референдуме высказались против этого документа. Причину этого мы склонны усматривать не только в особом отношении ирландцев к усилению европейских интеграционных процессов, но и в постепенном изменении подходов как властных структур, так и самих избирателей к институтам непосредственной демократии, в особенности, когда это касается вопросов, связанных с делегированием реализации суверенных полномочий международным структурам.

В третью категорию референдумов, связанных с членством в Европейском Союзе, можно отнести референдумы о выходе из состава ЕС, проведённые в Великобритании. Для обозначения процесса выхода Великобритании из состава Европейского Союза был введён специальный термин - Brexit (Брекзит). Он образован путём слияния сокращений слов «Britain» (Британия) и «Exit» (выход). Аналогично этому для обозначения возможного выхода Греции из ЕС ранее был использован термин «Grexit».

Если на первом референдуме, проведённом в 1975 г., был получен отрицательный результат, то на втором, состоявшемся 23 июня 2016 г., большинство проголосовавших поддержали выход этого государства из состава Европейского Союза. На референдуме по Brexit ${ }^{1} 51,9$ \% проголосовавших высказались за выход Великобритании из EC, а 48,1 \% - за то, чтобы Великобритания осталась в составе ЕС. Такой неожиданный результат референдума вызвал большой резонанс в не только в Великобритании и Европе, но и во всём мире. Британское правительство оказалось в непростом положении. Лидер правящей Консервативной партии премьер-министр Дэвид Камерон подал в отставку, и уже 11 июля после внутрипартийного голосования новым лидером партии стала Тереза Мэй. С 13 июля она была назначена премьер-министром Соединённогом Королевства. Среди общественности распространялся протест против Brexit, ведь с юридической точки зрения референдум прямо не предусматривал выход Великобритании из Союза Первый министр Шотландии Никола Стерджен высказывалась за наложение вето парламентом Шотландии на выход Великобритании из ЕС

Однако с политической точки зрения, любая партия, которая бы пыталась обжаловать результаты народного волеизъявления, угрожала бы демократическим традициям, и такие действия могли бы существенно подорвать не только авторитет британского правительства, но и вызвать массовые волнения. Учитывая это, Тереза Мэй недвусмысленно обозначила характер будущих отношений, четко отметив, что Brexit является неотвратимым. Это заявление дало основания считать, что новая премьер-министр приложит максимум усилий для того, чтобы без компромиссов

${ }^{1}$ «Br» (англ. Великобритания) + «ехіt» (англ. выход). 
инициировать выход Великобритании из ЕС по процедуре, установленной в статье 50 Договора о Европейском Союзе.

Согласно тексту Договора о ЕС, каждый член Союза может оставить объединение согласно собственным конституционным требованиям. Для этого государство сообщает Европейскому совету о таком намерении. Согласно инструкций, предоставленным Европейским советом, ЕС обязано провести переговоры и достичь соглашения по особенностям процесса выхода государства из объединения, учитывая дальнейшие отношения после выхода. Такое соглашение может быть достигнуто квалифицированным большинством Европейского совета после согласия Европейского парламента. При этом государство, задействовавшее статью 50, уже не участвует в совещаниях Европейского совета, а момент прекращения его членства определяется в достигнутом соглашении или наступает автоматически через два года после применения статьи 50 [18].

В конце января 2017 г. Верховный суд Великобритании постановил, что статья 50 Договора - EC не может быть задействована правительством без одобрения обеими палатами парламента. Уже 1 февраля 2017 г. депутаты Парламента Соединенного Королевства в первом чтении 498 голосами против 114 поддержали законопроект о выходе из ЕС, а 2 февраля правительство опубликовало так называемую «Белую книгу» (окончательный вариант программы правительства) по выходу из Евросоюза [26]. Позже законопроект был одобрен обеими палатами британского парламента и 16 марта 2017 г. подписан королевой Елизаветой II. 29 марта 2017 г. премьер-министр Великобритании Тереза Мэй подписала письмо на имя главы Евросовета Дональда Туска с уведомлением властей Европейского Союза о начале процедуры выхода Соединенного Королевства из ЕС [21].

Полноценные переговоры с Европейским советом по особенностям соглашения между Великобританией и ЕС начались только после того, как Великобритания провела внеочередные парламентские выборы 8 июня 2017 г. Данные выборы, которые были инициированы Терезой Мэй с целью обеспечить поддержку выбранного курса на выход из ЕС, не откладывали переговоры, по- тому что по словам представителей Европейской комиссии, переговоры в любом случае должны были происходить не раньше лета 2017 г.

В рамках подготовки к этим переговорам в EC в конце марта были приняты ключевые принципы, на основе которых будут проводиться переговоры. Самым сложным вопросом должно было стать будущее торговых отношений между Великобританией и ЕС. Если в “черновом» варианте речь шла о готовности ЕС работать для достижения полноценного соглашения о свободной торговле, то уже в апреле 2017 г. обновленные принципы предусматривали только желание возможного рассмотрения вопроса «соглашения о торговле». В этом документе было также указано, что членство в ЕС должно быть выгодным, и Великобритания в любом случае должна потерять определенные торговые привилегии. Что касается самого международного договора о выходе, то первый проект Соглашения о выходе был представлен в марте 2018 г., последняя на сегодняшний день опубликованная редакция датируется ноябрём 2018 г. [17].

В заключение следует отметить, что ресерендумы как приоритетная форма прямого народовластия продолжают свой генезис на качественно новом уровне: расширяется круг стран, практикующих референдумы с целью принятия общественно значимых решений; увеличивается круг вопросов, выносимых на всенародное голосование, а сами рефререндумы, проводимые в отдельных государствах, приобретает не только общенациональное, но и международное значение. В особенности это подтверждается практикой Европейского Союза, в котором успех референдумов в начале XXI в., по-прежнему зависит от готовности общества решать важные дела публично и доброй воли политической элиты государства способствовать этим стремлениям народа. В любом случае, можно с полной уверенностью утверждать, что результаты целого ряда референдумов, в частности, в Ирландии, оказывали серьёзное влияние на функционирование EC, развитие его правовой системы. А результаты рефререндума по Brexit ознаменовали совершенно новый этап в развитии всего процесса европейской интеграции, который до того момента рассматривался как необратимый

\section{Литература}

1. Авакьян С. А. Конституционное право России: в 2 т. Т.1. М.: Норма: ИНФРА-М, 2011. 864 с

2. Воронков Л. С. О многообразии интеграционных процессов в Европе // Вестник МГИМО Университета. 2013. №4 (31). C. 98-105.

3. Галушко Д. В. Правовые и институционные основы взаимодействия Ирландии и Европейского союза: монография. Воронеж: Издательско-полиграфический центр ВГУ, 2008. 187 с.

4. Галушко Д. В. О суверенитете государства в международном праве // Вестник Воронежского государственного университета. Серия: Право. 2013. №1 (14). С. 366-374.

5. Галушко Д. В. Международно-правовые проблемы правосубъектности государств (на примере Ирландии): монография. М.: Юрлитинформ, 2017. 224 с.

6. Галушко Д. В. Взаимодействие права Европейского союза с правом государств-членов и третьих стран: монография. Воронеж: Издательский дом ВГУ, 2018. 186 с.

7. Зверева Т. В. О референдумах в Европейском союзе // Вестник Дипломатической академии МИД России. Россия и мир. 2016. №4 (10). С. 45-57. 
8. Кембаев Ж. М. Региональная интеграция в Евразии: основные признаки, проблемы и перспективы // Российский юридический журнал. 2016. №1. С. 32-45.

9. Кембаев Ж. М. Сравнительно-правовой анализ Комиссий Евразийского и Европейского Союзов // Современное право. 2012. №12. С.129-132.

10. Марченко М. Н. Государственный суверенитет: проблемы определения понятия и содержания // Правоведение. 2003. №1. C. 186-197.

11. Машкова Е. В. Особенности формирования и новые тенденции развития межрегиональной зоны свободной торговли, созданной Европейской ассоциацией свободной торговли // Пробелы в российском законодательстве. 2016. №8. C. 389-395. L.73.

12. Act concerning the conditions of accession and the adjustments to the treaties (1972) // Official Journal. 27.03.1972.

13. Bjørklund T. Old and New Patterns: The «No» Majority in the 1972 and 1994 EC/EU Referendums in Norway // Acta Sociologica. 1997. No.40. P.143-159.

14. Buchan D. Outsiders on the Inside: Swiss and Norwegian Lessons for the UK. London: Centre for European Reform, 2012. URL: http://www.cer.org.uk/sites/default/files/publications/ attachments/pdf/2012/buchan_swiss_norway_11oct126427.pdf (Accessed: 01.07.2019).

15. Butcher P., Stratulat C. The European Citizens' Consultations: Evaluation report. European Policy Centre. URL: http:// www.epc.eu/pub_details.php?cat_id=1\&pub_id=8839\&year=2018 (Accessed: 01.07.2019).

16. Consolidated version of the Treaty on European Union OJ C 202, 7.6.2016, p. 13-388 (EN). URL: https://eur-lex. europa.eu/legal-content/EN/TXT/?uri=CELEX:12016M/TXT (Accessed: 01.07.2019).

17. Draft Agreement on the withdrawal of the United Kingdom of Great Britain and Northern Ireland from the European Union and the European Atomic Energy Community, as agreed at negotiators' level on 14 November 2018. URL: https:// ec.europa.eu/commission/sites/beta-political/files/draft_withdrawal_agreement_0.pdf (Accessed: 01.07.2019).

18. Fossum J.E. Norway's European conundrum // ARENA Working Papers. 2009. No. 4. URL: https://www.sv.uio.no/ arena/english/research/publications/arena-working-papers/2001-2010/2009/WP04_09.pdf (Accessed: 01.07.2019).

19. Hathaway O. A. International Delegation and State Sovereignty. URL: http://scholarship.law.duke.edu/cgi/viewcontent cgi?article=1455\&context=Icp (Accessed: 01.07.2019).

20. Miller V. The Treaty of Lisbon after the Second Irish Referendum. URL: https://www.voltairenet.org/IMG/pdf/Treaty_of_ Lisbon_after_the_Second_Irish_Referendum.pdf (Accessed: 01.07.2019).

21. Prime Minister's letter to Donald Tusk triggering Article 50. URL: https://www.gov.uk/government/publications/primeministers-letter-to-donald-tusk-triggering-article-50 (Accessed: 01.07.2019).

22. Setālä M., Schiller T. Referendums and representative democracy: Responsiveness, accountability and deliberation New York: Routledge, 2009.

23. Sovereignty in Transition / Ed. Walker N. Portland: Hart Publishing, 2003.

24. The Constitution of the Republic of Estonia. URL: https://www.riigiteataja.ee/en/eli/530102013003/consolide (Дата обращения: 01.07.2019).

25. The Constitution of Ireland. URL: http://www.irishstatutebook.ie/eli/cons/en (Accessed: 01.07.2019).

26. The United Kingdom's exit from and new partnership with the European Union // UK Government. London, 2017. URL: https://www.gov.uk/government/publications/the-united-kingdoms-exit-from-and-new-partnership-with-the-european-unionwhite-paper (Accessed: 01.07.2019).

27. Treaty between the Member States of the European Communities and the Kingdom of Denmark, Ireland and the United Kingdom of Great Britain and Northern Ireland concerning the accession of the Kingdom of Denmark, Ireland and the United Kingdom of Great Britain and Northern Ireland to the European Economic Community and the European Atomic Energy Community (1972) // Official Journal. 27.03.1972. P. 73.

28. Treaty concerning the accession of Norway, Austria, Finland and Sweden to the European Union // Official Journal. 29.08.1994. P. 241.

\section{References}

1. Avak'jan S. A. Konstitucionnoe pravo Rossii: v 2 t. (Constitutional law of Russia: in 2 vol.) Vol.1. Moscow: Norma: INFRA-M publ., 2011. (In Russian)

2. Voronkov L. S. O mnogoobrazii integracionnyh processov v Evrope (On the diversity of integration processes in Europe) // Vestnik MGIMO Universiteta. 2013. № 4 (31). P. 98-105. (In Russian)

3. Galushko D. V. Pravovye i institucionnye osnovy vzaimodejstvija Irlandii i Evropejskogo sojuza: monografija (Legal and institutional foundations of the interaction of Ireland and the European Union: monograph). Voronezh: Izdatel'skopoligraficheskij centr VGU, 2008. (In Russian)

4. Galushko D. V. O suverenitete gosudarstva $\vee$ mezhdunarodnom prave (On the state sovereignty in international law) /I Vestnik Voronezhskogo gosudarstvennogo universiteta. Serija: Pravo. 2013. № 1 (14). P. 366-374. (In Russian)

5. Galushko D. V. Mezhdunarodno-pravovye problemy pravosub'ektnosti gosudarstv (na primere Irlandii): monografija (The international legal problems of legal personality of states (by the example of /reland). Moscow: Jurlitinform publ., 2017. (In Russian)

6. Galushko D. V. Vzaimodejstvie prava Evropejskogo sojuza s pravom gosudarstv-chlenov i tret'ih stran: monografija (Relationships between EU law and law of member-states and third countries: monograph). Voronezh: VSU publ., 2018. (In Russian)

7. Zvereva T. V. O referendumah v Evropejskom sojuze (On referenda in the European Union) // Vestnik Diplomaticheskoj akademii MID Rossii. Rossija i mir. 2016. No.4 (10). P. 45-57. (In Russian) 
8. Kembaev Zh. M. Regional'naja integracija v Evrazii: osnovnye priznaki, problemy i perspektivy (Regional integration in Eurasia: key features, problems and prospects) // Rossijskij juridicheskij zhurnal. 2016. No.1. P. 32-45. (In Russian)

9. Kembaev Zh. M. Sravnitel'no-pravovoj analiz Komissij Evrazijskogo i Evropejskogo Sojuzov (Comparative legal analysis of the Commissions of the Eurasian and European Unions) // Sovremennoe pravo. 2012. No.12. P. 129-132. (In Russian)

10. Marchenko M. N. Gosudarstvennyj suverenitet: problemy opredelenija ponjatija i soderzhanija (State sovereignty: problems of defining the concept and content) // Pravovedenie. 2003. No.1. P. 186-197. (In Russian)

11. Mashkova E. V. Osobennosti formirovanija i novye tendencii razvitija mezhregional'noj zony svobodnoj torgovli, sozdannoj Evropejskoj associaciej svobodnoj torgovli (Features of formation and new development trends of the interregional free trade zone created by the European Free Trade Association) // Probely v rossijskom zakonodatel'stve. 2016. No.8 P. 389-395. (In Russian).

12. Act concerning the conditions of accession and the adjustments to the treaties (1972) // Official Journal. 27.03.1972 L.73.

13. Bjørklund T. Old and New Patterns: The «No» Majority in the 1972 and $1994 \mathrm{EC} / \mathrm{EU}$ Referendums in Norway // Acta Sociologica. 1997. No.40. P. 143-59.

14. Buchan D. Outsiders on the Inside: Swiss and Norwegian Lessons for the UK. London: Centre for European Reform, 2012. URL: http://www.cer.org.uk/sites/default/files/publications/ attachments/pdf/2012/buchan_swiss_norway_11oct126427.pdf (Accessed: 01.07.2019).

15. Butcher P., Stratulat C. The European Citizens' Consultations: Evaluation report. European Policy Centre. URL: http:// www.epc.eu/pub_details.php?cat_id=1\&pub_id=8839\&year=2018 (Accessed: 01.07.2019).

16. Consolidated version of the Treaty on European Union OJ C 202, 7.6.2016, p. 13-388 (EN). URL: https://eur-lex. europa.eu/legal-content/EN/TXT/?uri=CELEX:12016M/TXT (Accessed: 01.07.2019).

17. Draft Agreement on the withdrawal of the United Kingdom of Great Britain and Northern Ireland from the European Union and the European Atomic Energy Community, as agreed at negotiators' level on 14 November 2018. URL: https:// ec.europa.eu/commission/sites/beta-political/files/draft_withdrawal_agreement_0.pdf (Accessed: 01.07.2019).

18. Fossum J.E. Norway's European conundrum // ARENA Working Papers. 2009. No. 4. URL: https://www.sv.uio.no/ arena/english/research/publications/arena-working-papers/2001-2010/2009NNP04_09.pdf (Accessed: 01.07.2019).

19. Hathaway O. A. International Delegation and State Sovereignty. URL: http://scholarship.law.duke.edu/cgi/viewcontent. cgi?article $=1455 \&$ context=lcp (Accessed: 01.07.2019).

20. Miller V. The Treaty of Lisbon after the Second Irish Referendum. URL: https://www.voltairenet.org/IMG/pdf/Treaty_of_ Lisbon_after_the_Second_Irish_Referendum.pdf (Accessed: 01.07.2019).

21. Prime Minister's letter to Donald Tusk triggering Article 50. URL: https://www.gov.uk/government/publications/primeministers-letter-to-donald-tusk-triggering-article-50 (Accessed: 01 .07.2019).

22. Setälā M., Schiller T. Referendums and representative democracy: Responsiveness, accountability and deliberation. New York: Routledge, 2009

23. Sovereignty in Transition / Ed. Walker N. Portland: Hart Publishing, 2003

24. The Constitution of the Republic of Estonia. URL: https://www.riigiteataja.ee/en/eli/530102013003/consolide (Дата обращения: 01.07.2019).

25. The Constitution of Ireland. URL: http://www.irishstatutebook.ie/eli/cons/en (Accessed: 01.07.2019).

26. The United Kingdom's exit from and new partnership with the European Union // UK Government. London, 2017. URL: https://www.gov.uk/government/publications/the-united-kingdoms-exit-from-and-new-partnership-with-the-european-unionwhite-paper (Accessed: 01.07.2019).

27. Treaty between the Member States of the European Communities and the Kingdom of Denmark, Ireland and the United Kingdom of Great Britain and Northern Ireland concerning the accession of the Kingdom of Denmark, Ireland and the United Kingdom of Great Britain and Northern Ireland to the European Economic Community and the European Atomic Energy Community (1972) // Official Journal. 27.03.1972. P.73.

28. Treaty concerning the accession of Norway, Austria, Finland and Sweden to the European Union // Official Journal. 29.08.1994. P. 241

\section{Сведения об авторе}

Галушко Дмитрий Вячеславович - кандидат юридических наук, доцент кафедры теории государства и права, международного права и сравнительного правоведения Воронежского государственного университета (Воронеж) / galushkodv@gmail.com

\section{Information about the author}

Galushko Dmitriy - PhD in Law, Associate Professor, Chair of Theory of State and Law, International Law and Comparative Law, Voronezh State University (Voronezh) / galushkodv@gmail.com 